\title{
Examination of Stick-slip Scenario on Lubricated Spring-brake Systems
}

\author{
Ilaria Ghezzi ${ }^{1,2,3}$, Davide Tonazzi ${ }^{2}$, Michael Rovere ${ }^{3}$, Cedric Le Coeur ${ }^{3}$, Gilles Pradel $^{3}$, Yves Berthier ${ }^{1}$, Francesco \\ Massi $^{2}$ \\ ${ }^{1}$ INSA-Lyon, CNRS UMR5259, LaMCoS, F-69621, France, ilaria.ghezzi@insa-lyon.fr and yves.berthier@insa-lyon.fr \\ ${ }^{2}$ Department of Mechanical and Aerospace Engineering, "La Sapienza”" University of Rome, Italy, davide.tonazzi@uniroma1.it \\ and francesco.massi@uniroma1.it \\ ${ }^{3}$ Somfy S.A., R\&D Center, Cluses, France, michael.rovere@somfy.com, cedric.le.coeur@somfy.com, gilles.pradel@somfy.com
}

\begin{abstract}
Several complex mechanisms can be responsible for undesirable friction-induced vibrations in many mechanical systems. This paper presents a tribological and dynamic analysis of the stick-slip problem, under greased lubrication, taking into account the practical application of a spring-brake system used in electric tubular motors. The main functioning of these brakes is based on the frictional greased contact between a stationary cylinder and a torsional spring, which rotates inside it. The identification of the parameters that most affect the stick-slip appearance in greased contacts requires a complete understanding and appropriate analysis of the entire system, to identify the effects of all physical parameters on the system. Here the global dynamics and the local contact behaviour is analysed, providing an in-depth examination of the stick-slip phenomenon on a greased contact.

Keywords-- Stick-slip, contact instabilities, tribology, greased contact, brake systems.
\end{abstract}

\section{INTRODUCTION}

Nowadays, in the field of applied mechanics and tribology, one of the most important challenges is the ability to predict and reduce surface damages [1], failure of machine components [2] and undesirable frictional and dynamic characteristics [3]. In particular, the appearance of frictioninduced vibrations at the contact is hardly controllable and can result in high local contact pressure, elevated stresses, system oscillations, discontinuous motion and fastidious noise [4]. Friction-induced vibrations and related issues have received considerable attention from a number of researchers [5]-[7], but there are still no general solving methods to completely eliminate or reduce instabilities. Solving the problem requires a complete understanding and appropriate analysis of the entire system, to identify the effects of all physical parameters on the system. This study focuses on the stick-slip phenomenon [8], in order to guarantee appropriate design of the investigated brake systems.

Stick-slip vibration is generally characterized by a sawtooth displacement-time evolution, which has clearly defined as stick and slip phases, in which the two surfaces in contact stick and slip over each other. Several studies highlighted that one of the possible stick-slip mechanisms is due to the velocity-dependence of the macroscopic friction [9]. The motion is governed by a static friction force in the stick phase and a velocity dependent kinetic friction force in the slip phase
[10], [11]. So, one of the most widely accepted cause for stickslip is that the macroscopic static friction coefficient $\left(\mu_{\mathrm{s}}\right)$ is markedly greater than the kinetic friction coefficient $\left(\mu_{\mathrm{k}}\right)$ or, more rigorously, that $\mu \mathrm{k}$ drops rapidly at small speeds [12]. Moreover, the unstable vibrational response can be affected by changes in local contact pressure, sliding velocity, component geometry, material properties, surface roughness, etc [13, 14]. The problem becomes more complicated when lubricated contact interfaces are involved. Lubricated systems are supposed to reduce the frictional losses and improve the lifetime of mechanical components, but they can also affect undesirable vibrations, due to a complex frictional-velocity path [15]-[18].

Therefore, object of the present study is the examination of stick-slip vibrations in a greased contact. The analysis will be focused on spring-brakes used in electric tubular motors. Both the local contact behaviour and the system dynamic response are investigated, to identify the stick-slip phenomenon during the frictional relative motion.

First, the system under investigation is described. The examined mechanical system is brought into limit conditions for which the appearance of the stick-slip instabilities may occur. In this way, the phenomenon can be investigated.

Then, system dynamic response is analysed, together with the observation of the "traces" of stick-slip in the frictional surfaces. Finally, the local contact behaviour is investigated through experimental tests on a simplified system, with the aim of a better understanding of the local contact response.

The possibility of understanding the conditions for which the system is more predisposed to the stick-slip phenomenon may allow for preventing the appearance of such instabilities and the related noise emission before its occurrence.

\section{DESCRIPTION OF THE MECHANICAL SYSTEM}

A mechanical spring-brake system is taken into account as example of the analysis method of the stick-slip phenomenon appearance in greased contacts.

The used mechanical spring-brake is mounted on tubular actuators, which are subjected to many environmental and functional constraints. It must allow a strictly identical

Digital Object Identifier (DOI):

http://dx.doi.org/10.18687/LACCEI2019.1.1.484

ISBN: 978-0-9993443-6-1 ISSN: 2414-6390

$17^{\text {th }}$ LACCEI International Multi-Conference for Engineering, Education, and Technology: "Industry, Innovation, And

Infrastructure for Sustainable Cities and Communities”, 24-26 July 2019, Jamaica. 
operation in both directions of engine rotation and ensure the holding of the load [19]-[23]. Its concept is made up of four different components (Fig. 1[20]): the drum (1), the driver (2), the spring (3) and the side frame (4).

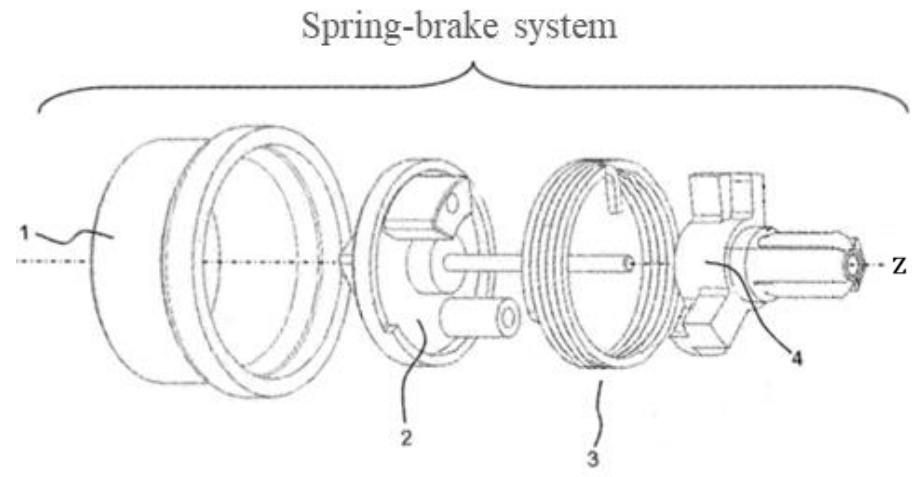

Fig. 1 [20] Exploded view of a spring-brake system. Identification of the main components: the drum (1), the driver (2), the spring (3) and the side frame (4).

The driver is stuck inside the drum, it is directly connected to the motor, and transmits the rotation to the entire brake system. The side frame (4) supports the output load (L).

During rotation $(\omega)$, the side frame is alternately in contact with the spring end part. During the braking phase (Fig. 2 [20]) the final part of the spring (3a) is constrained to the driver (2) while the other part of the spring (3b) is pushed by the side frame (4).

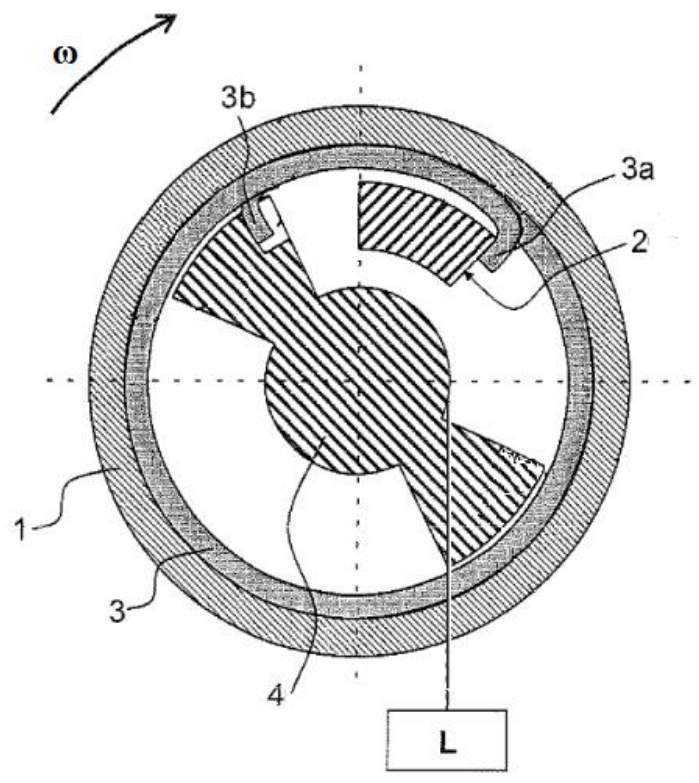

Fig. 2 [20] Schematic illustrations of the spring-brake structure in front view during the rotation $\omega$, lowering the load $\mathrm{L}$. The spring (3) geometry allow the direct contact between one of its end (3a) and the driver (2) and between the other end ( $3 b$ ) and the side frame (4).
Consequently, the spring, expanding the external diameter, is pressed against the internal surface of the drum allowing the braking. Lubricant grease is present between the drum (1) and the spring (3).

The interaction of the local contact response and the dynamics of the whole frictional system is at the basis of the stick-slip occurrence.

\section{STICK-SLIP DYNAMIC AND TRIBOLOGICAL ANALYSES}

As explained in the introduction, the stick-slip phenomenon is influenced by the coupling of local contact response and the dynamics of the whole frictional system. Then, it is necessary to have an in-depth knowledge of how the involved parameters affect locally and globally the system response.

A. Analysis of the system dynamic response

In order to evaluate the dynamic response of the system, an accelerometer (B) is placed on the external case (A) of the actuator (Fig. 3). The acceleration signal is then analysed to evaluate the presence of instabilities arising from frictioninduced vibrations at the contact between spring and drum. The tests are performed imposing a high load (L) of $70 \mathrm{~N}$ and a speed regime of $354 \mathrm{rpm}$.

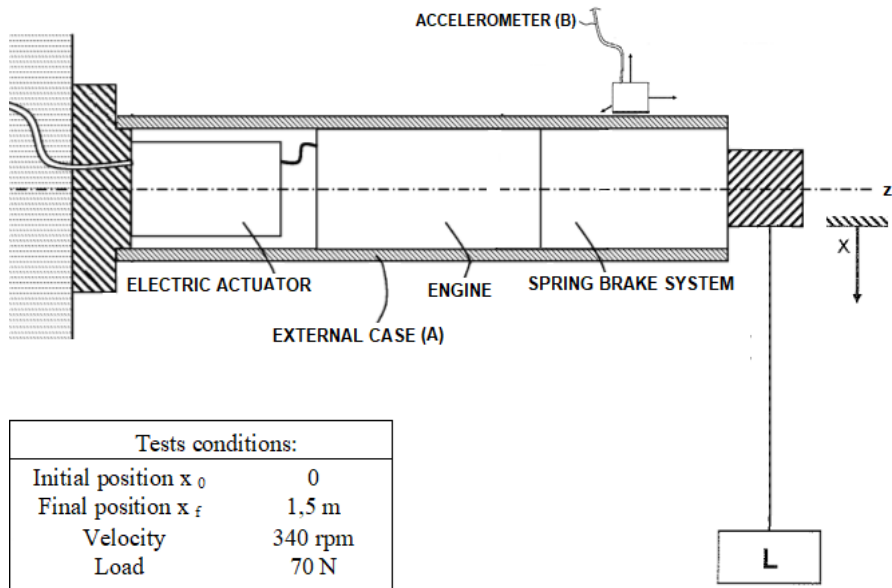

Fig. 3 [21] Schematic illustrations of the tests performed to evaluate the dynamic response of the system during the rotation $\omega$ with the load $\mathrm{L}$. The accelerometer (B) is placed on the external case (A) close to the brake system.

The weight is fed up and down continuously for a total number of cycles equal to 10 . Figure 4 shows the response acquired with the accelerometer, during the braking phase of the weight (descending phase), at the second and the sixth cycle. It is possible to highlight the dynamic vibrational response, which is different with the increase of the number of cycles and, therefore, with the increasing of the internal temperature of the brake.

$17^{\text {th }}$ LACCEI International Multi-Conference for Engineering, Education, and Technology: "Industry, Innovation, And 


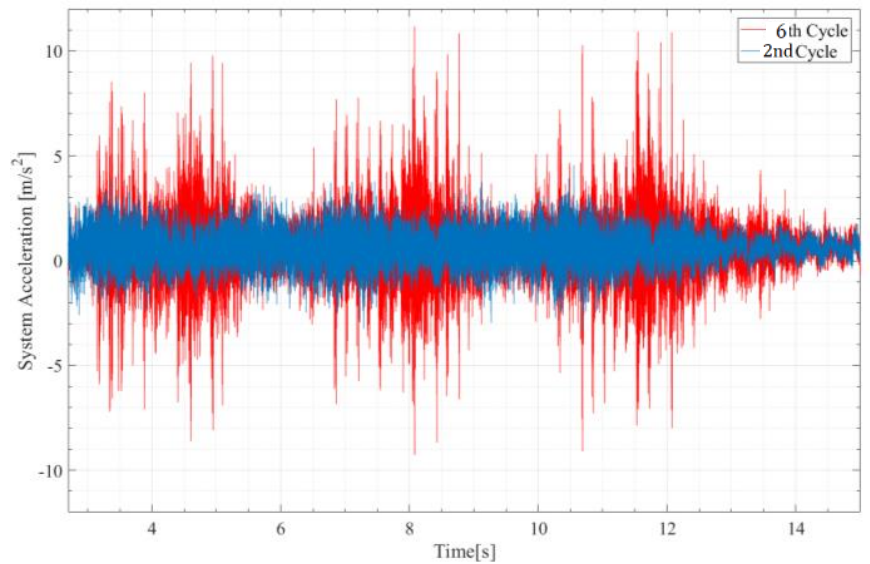

Fig. 4 Acceleration of the system in function of the time for the signal acquired during the load descent phase at the second cycle (blue line) and at the sixth cycle (red line).

When increasing the number of cycles, the temperature increases from ambient temperature $\left(2^{\text {nd }}\right.$ cycle at $\left.25^{\circ} \mathrm{C}\right)$ to a higher operative temperature $\left(6^{\text {th }}\right.$ cycle at $\left.70^{\circ} \mathrm{C}\right)$. While at ambient temperature no instabilities are detected, there are impulsive variations of the system acceleration when the temperature increases (Fig. 4).

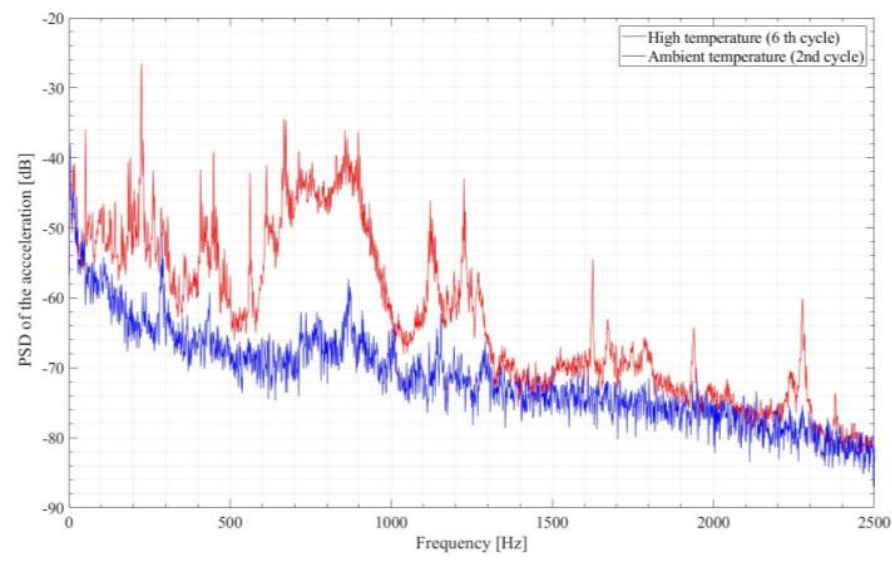

Fig. 5 Power Spectral Density (PSD) of the acceleration in function of the frequency for the signal acquired during the load descent phase at the first cycle (blue line) and at the twentieth cycle (red line).

Fig, 5 shows the Power Spectral Density (PSD) of the acceleration for the signal acquired during the load descent phase at both the $2^{\text {nd }}$ cycle (blue line) and at the $6^{\text {th }}$ cycle (red line). It is possible to observe the difference between the two dynamic responses.

In the first case (blue line), when the system is at ambient temperature $\left(25^{\circ} \mathrm{C}\right)$, the braking phase proceeds without instabilities and the power spectral density (PSD) of the acceleration reveals exclusively low amplitude vibrations, due to the regular functioning of the system. On the contrary, analysing the PSD at high temperature (red line) we can notice that the spectrum of the acceleration shows an overall higher energy content. This is consequence of the impulsive excitations, due to the stick-slip intermittences, which excite the system modes. The performed tests showed that the instabilities occur only after a certain number of cycles, when the brake temperature reaches about $70^{\circ} \mathrm{C}$.
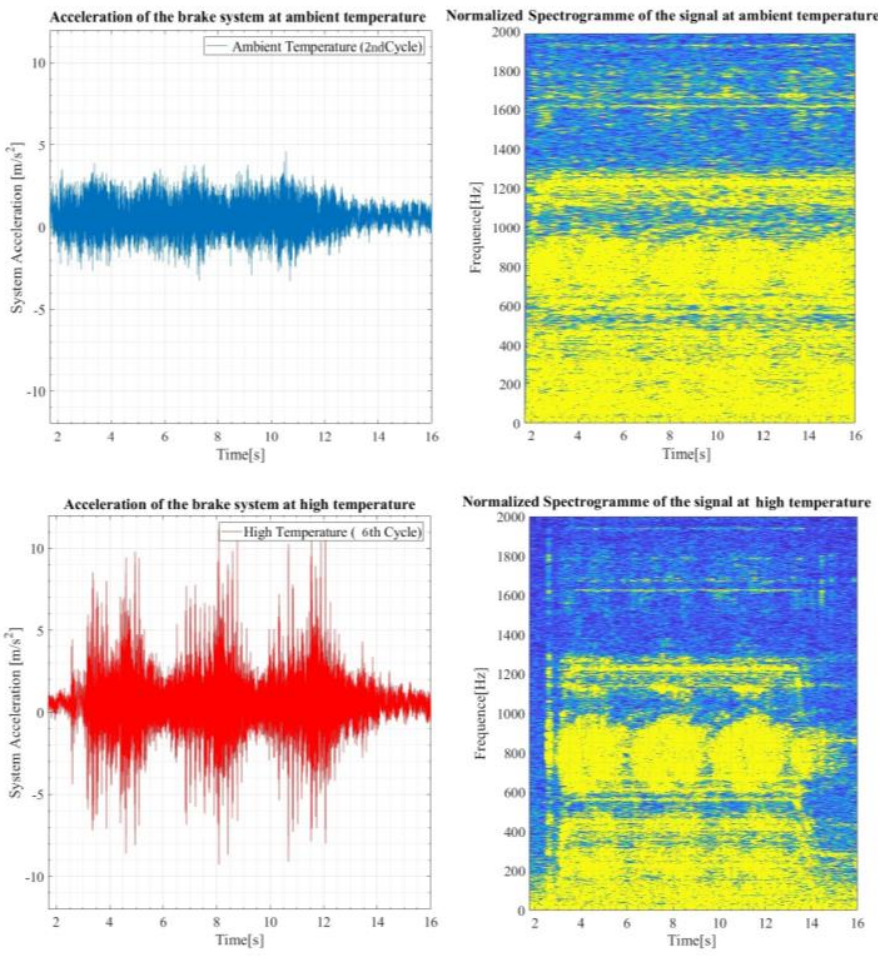

Fig. 6 Spectrogram of the two analysed signals. Above the acceleration signal of test performed at ambient temperature and its spectrum. Below, the acceleration signal of test performed at high temperature and its spectrum.

Figure 6 shows the spectrogram of the dynamic response of the system with and without stick-slip. The colour-map is proportional to the frequency vibration spectrum, as a function of the time. In the upper part of Figure 6, the results of the tests performed at ambient temperatures are highlighted. The horizontal lines correspond to the frequencies of the system under analysis, which are modes naturally excited during the normal functioning of the system.

The spectrogram of the acceleration measured during the $6^{\text {th }}$ cycle (Fig. 6, down), shows vertical lines which correspond to the acceleration response to the impulsive excitations due to stick-slip.

These excitations of the system dynamics are periodic and they repeat at each stick-slip cycle, exciting the modes of the system with a higher energy content. These impulsive excitations are due to an instable behaviour of the greased contact system. The analysis of the spectrum enables the detection of the stick-slip phenomenon appearance. 
Having therefore identified the two brake behaviours by the system dynamic response, it is useful to analyse the topography of the contact surfaces both in absence and in presence of vibrational instabilities.

\section{B. Analysis of the contact surface topography}

Aim of this section is the analysis of the instabilities through a direct analysis of the contact surface topographies. Two brake systems have been dismounted after braking, respectively with ant without stick-slip instabilities, and analysed with an optical and a Scanning Electron Microscope (SEM). The contact surfaces between the side-frame (Fig. 2 part 4) and the spring (Fig. 2 part 3b) are here analysed. This contact is representative of the movement of the spring. During the descending phase, this contact supports the load (L) and is affected by all the movements of the ending part of the spring. In particular, in the case of the presence of stick-slip instabilities, the part under analysis will be directly affected by the induced vibrations caused by the frictional contact (i.e. spring-drum contact). Figure 7 shows the images of the sideframe in the case of the brake without instabilities and those of the brake after stick-slip instabilities.

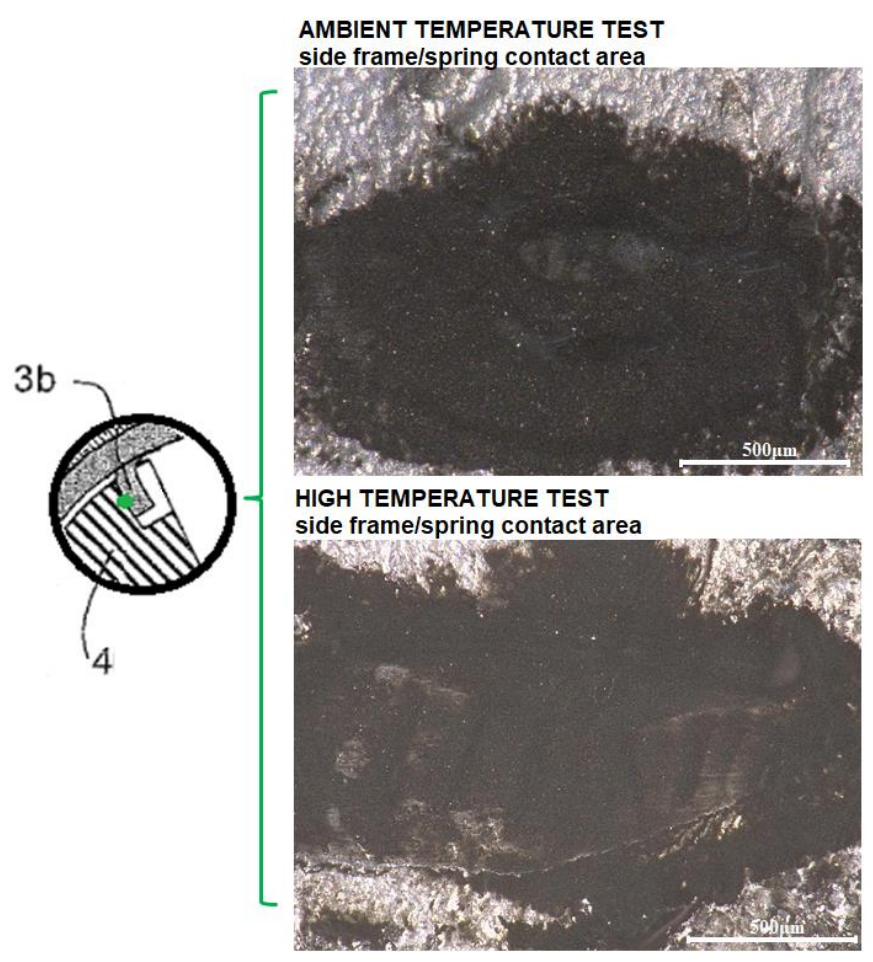

Fig. 7 Topographic images, obtained with an optical microscope, of the sideframe (4) in the contact area (green dot) between the end part of the spring

(3b) and the side-frame (4). The figure in the upper position represents contact area of the brake after braking without instabilities. The lower figure represents the contact area of the brake after braking with stick-slip instabilities.

As shown in the images in Figure 7, the contact zone between the spring and the side-frame is well defined in both cases (with and without stick-slip). The contact zone is covered by a uniform layer of grease. In the case of tests with stick-slip, vertical traces on the contact zone are observed. These traces are parallel to the drum axis ( $\mathrm{z}$ axis in Fig. 1). This means that during the brake rotation, the stick-slip imposes a movement of the torsional spring perpendicular to the $\mathrm{z}$ axis. The vertical traces identify therefore an axial displacement of the spring, which is not observed during braking in nominal operating conditions (without stick-slip). For a more in-depth analysis, the surfaces have been observed by SEM. First, the two sideframes of the brake systems are ultrasonically cleaned in an ethanol bath for 5 minutes and then in a heptane bath for another 5 minutes. Through this procedure it is possible to remove all traces of impurities and grease on the surfaces.

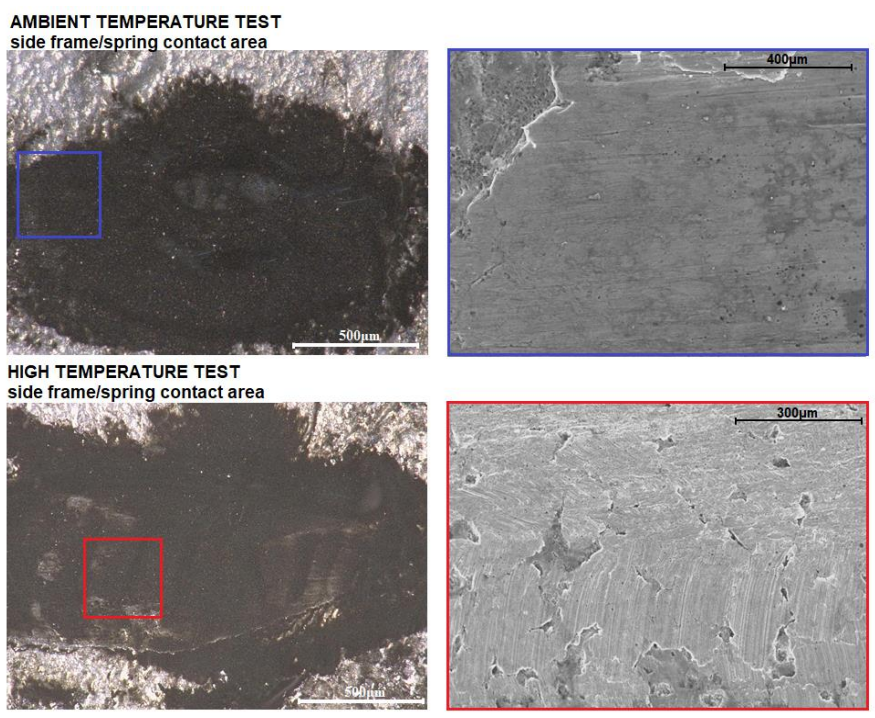

Fig. 8 Images obtained with a scanning electronic microscope of the sideframe (4) in the contact area between the end part of the spring (3b) and the side-frame (4). On the left the contact area with the grease and on the right a zoom of the contact area after the cleaning procedure.

The figures in the upper position show the test performed at ambient temperature. The lower figures show the test performed at high operating temperature, so the brake stopped after the $6^{\text {th }}$ cycle.

Figure 8 shows the images, taken by means of an electronic scanning microscope (SEM), of the same contact area previously analysed. The signs of axial movement of the spring during the rotation are evident in the case of presence of stick-slip. On the contrary, in the case of braking without stickslip, there are only the traces of the radial movement of the spring, due to the normal operating conditions of the brake.

Then, the surface analysis of a brake having experienced stick-slip allowed for highlighting that, during braking, the torsional spring does not remain in the original position during frictional stick-slip instabilities. The attempt of the spring to open axially can cause a misalignment of the components, a modification of the spring stiffness, a degradation of the grease role and a localization of the contact pressure. In general,

$17^{\text {th }}$ LACCEI International Multi-Conference for Engineering, Education, and Technology: "Industry, Innovation, And Infrastructure for Sustainable Cities and Communities”, 24-26 July 2019, Jamaica. 
looking at the signal analysis previously performed and at the topography of the surfaces, the succession of stick phases and sliding phases on the contact are accompanied by the presence of traces of axial movement of the spring and an impulsive dynamic excitation of the system. This alternating movement of the spring is described by an alternation of static phases in which the system accumulates potential energy, alternated with dynamic phases in which the potential energy is released and excite the vibration of the system.

As explained in the first section, the occurring of vibrational instabilities is due to the interaction between the system dynamics and the local contact behaviour, which is here a greased lubricated contact. The dynamic of frictional system can thus become unstable, due to the coupling caused by the normal and frictional components of the contact forces, [5]. Moreover, several contact parameters can affect the response of the vibrating system [14], such as contact normal load, sliding velocity [24], surface roughness, component geometries, material properties, types and conditions of lubrication [16]. Each change in one of the contact parameters influences directly the contact dynamics and the response of the system, due to the mutual influence of the local response of the contact and the global system dynamics [4]. For this reason, after having analysed the overall system dynamic response of the brake, a further analysis has been performed to investigate the local frictional response of the greased contact in specific frictional tests.

\section{LOCAL GREASED CONTACT RESPONSE}

For understanding and controlling the stick-slip phenomenon, it is necessary to have an in-depth knowledge of how the involved parameters affect locally and globally the system behaviour.

One of the most widely accepted cause for stick-slip is that the static friction coefficient $\left(\mu_{\mathrm{s}}\right)$ is markedly greater than the kinetic friction coefficient $\left(\mu_{\mathrm{k}}\right)$ or, more rigorously, that $\mu_{\mathrm{k}}$ drops rapidly with respect to an increase of the speed [12].

Starting from these considerations and from the results obtained on the dynamic response of the system, a first experimental campaign has been carried out to identify the evolution of the friction coefficient as a function of speed and temperature. The tests were performed on the test bench called TriboAir (Fig. 9).

The relative movement of the drum is allowed by an air bearing system (2), coupled with a linear voice coil (1), assuring the absence of unwanted source of friction and vibrations, which could negatively influence the measures [25]. The linear voice coil (1) allows for a planar controlled movement of the base, where the drum is clamped. The velocity and displacement of the voice coil is determined by a controller and a linear optical encoder (4), which closes the position command loop.

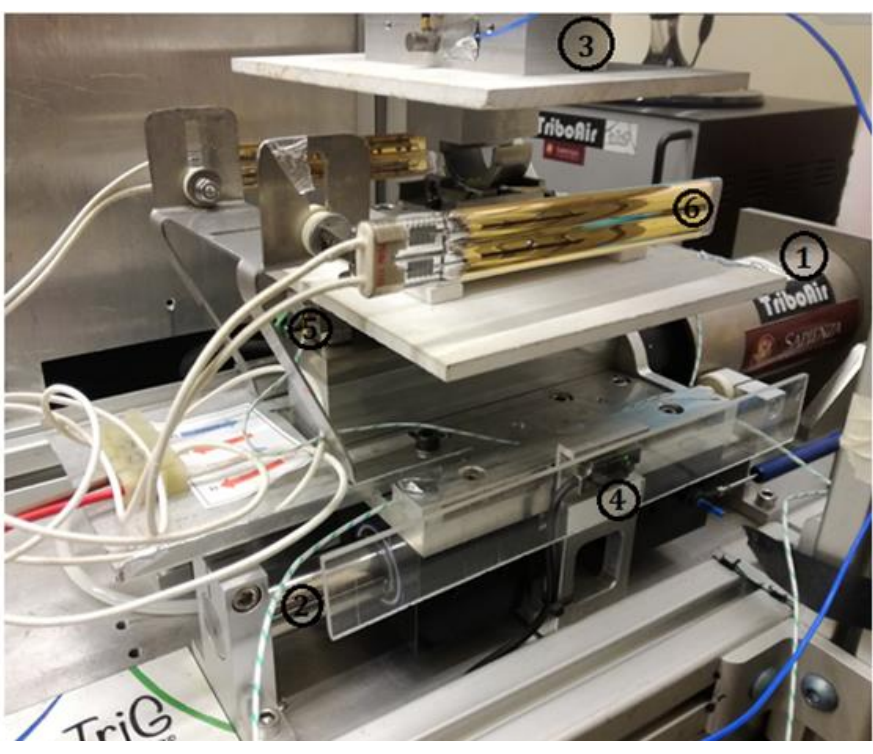

Fig. 9 TriboAir test bench where (1) identify the linear voice coil, (2) the air bearings system, (3) the loading system, (4) the linear encoder, (5) the 3-axial force transducers and (6) the infrared emitters.

Two 3-axial force transducers (5) are mounted on the translating base of the test bench, in order to measure the overall normal and tangential contact forces. Other two air bushings hold the upper sample and allow the application of the load (3), by dead weights, along the normal direction with respect to the contact. An accelerometer is used for measuring the vibrational response of the system during the movement. This system is especially designed for reproducing and measuring contact-induced vibrations without introducing parasite noise from other contact interfaces [26].

To perform tests at different temperatures, two infrared (IR) emitters are placed (6) on the side of the samples in contact, and two thermocouples are placed for monitoring the temperature of the samples. The signals are acquired by an 8 channels acquisition-card (NI 4472) with a sampling frequency of $5120 \mathrm{~Hz}$ and then post-processed by Matlab $\mathbb{C}$.

A simplified tribological system has been developed to measure the local frictional response of the contact under controlled boundary conditions (Fig. 10). The tests are performed on a drum cut in two parts and a sector of the spring coil (Fig. 10). In this way the same materials of the real brake systems are tested. The spire is fixed and the drum is moved along the tangential (x-axis) direction. The two contact surfaces are lubricated with grease before each test. A normal load (N) is imposed and the two surfaces are rubbed against each other along the tangential direction at controlled speed (v). The test campaign has been performed by varying the speed, temperature and imposed normal load. 


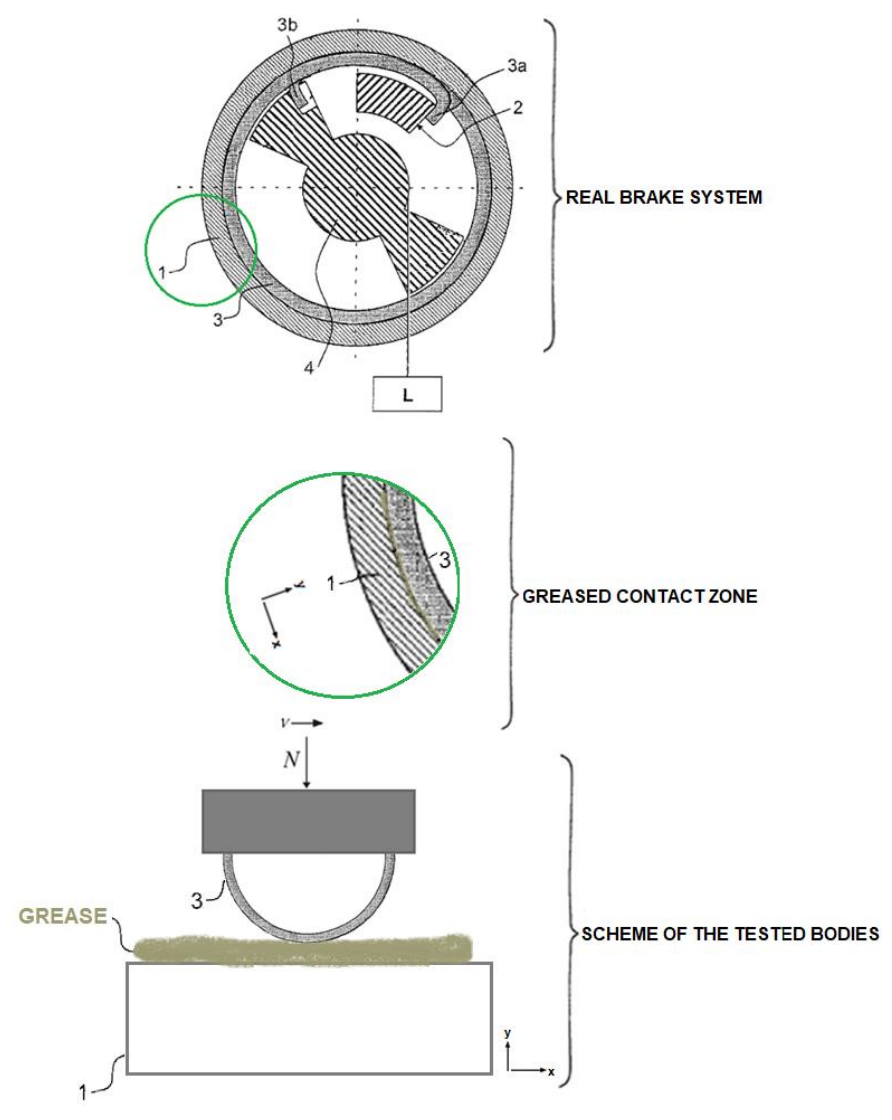

Fig. 10 Scheme of the tests performed on the TriboAir tests bench starting from the analysis of the real contact case. A normal load (N) and a displacement along the $\mathrm{x}$ axis with a velocity (v) are imposed to the spire that moves along the surface of the drum.

From the piezoelectric transducers (5), it is possible to recover the signal of the normal and tangential forces with respect to the different tested parameters.

The friction coefficient has been calculated for each test as the ratio between the tangential and normal forces. For the analysis of the dynamic friction coefficient the mean value of the signal recorded at constant velocity is considered.

The tested specimens, representative of the real system but with a reduced and controlled contact area, allow to control the boundary conditions at the contact. The conditions imposed in the presented test are constant speed, equal to $0,1 \mathrm{~mm} / \mathrm{s}$, and a total normal load equal to $70 \mathrm{~N}$. Figure 11 shows the velocity $([\mathrm{mm} / \mathrm{s}])$ imposed to the drum with the linear voice-coil (1) and the respective displacement of the drum acquired by the encoder (4).

The tests have been performed at both ambient $\left(22^{\circ} \mathrm{C}\right)$ and higher temperature $\left(70^{\circ} \mathrm{C}\right)$ in order to simulate the same condition of the real spring-brake after respectively 2 and 6 cycles, presented in section III.
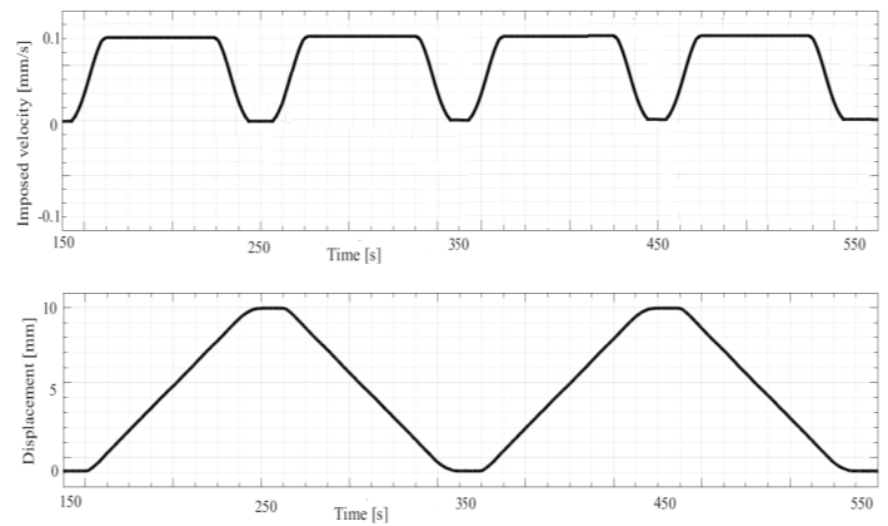

Fig. 11 Imposed velocity $[\mathrm{mm} / \mathrm{s}]$ in function of time [s] and the displacement $[\mathrm{mm}]$ of the drum in function of time [s].

Figure 12 shows the trend of the normalized friction coefficient as a function of time in the case of tests carried out at a speed of $0.1 \mathrm{~mm} / \mathrm{s}$, imposed load $70 \mathrm{~N}$, for both ambient (blue curve) and high temperature (red curve).
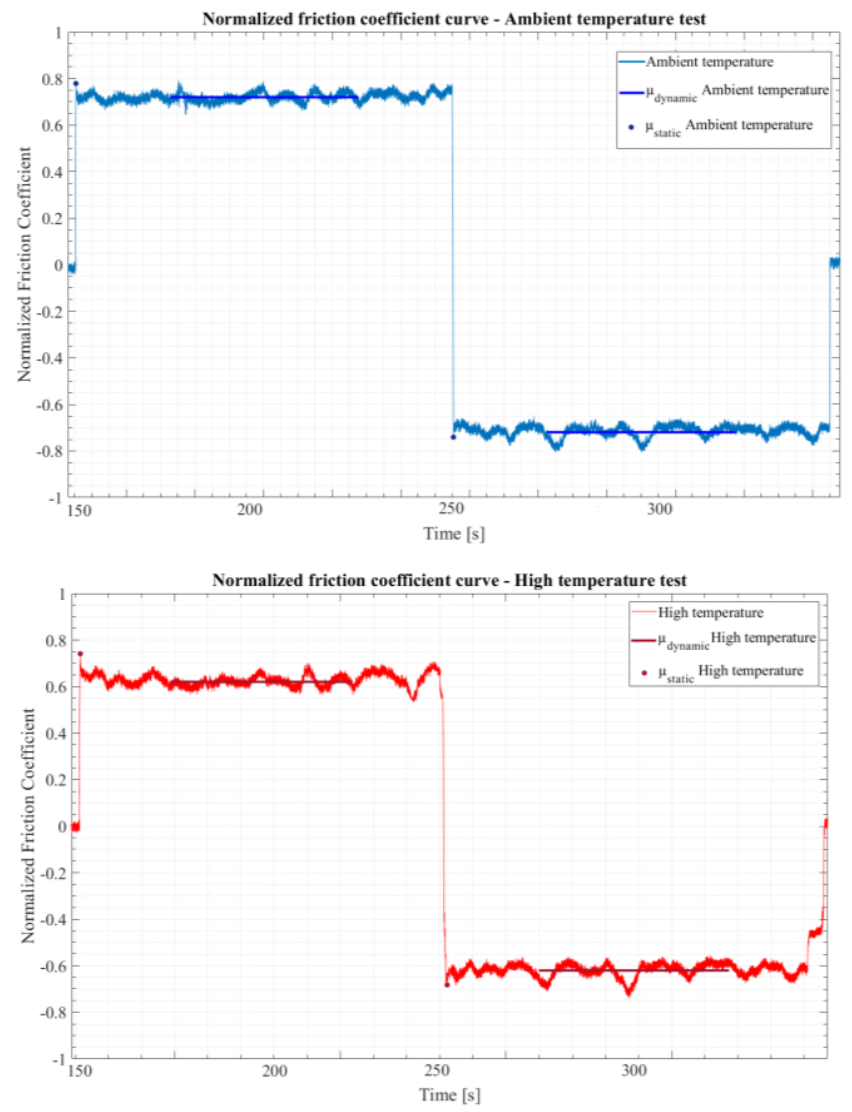

Fig. 12 Normalized friction coefficient behaviours in function of time. The figure in the upper position represent the test performed at ambient temperature, static (blue dot) and dynamic friction (blue line) coefficient are underlines. The figure in the lower position represent the test performed at higher temperature, static (red dot) and dynamic friction (red line) coefficient are underlines.

$17^{\text {th }}$ LACCEI International Multi-Conference for Engineering, Education, and Technology: "Industry, Innovation, And Infrastructure for Sustainable Cities and Communities", 24-26 July 2019, Jamaica. 
The obtained friction coefficient has been normalized for confidentiality. The trend of the friction coefficient is in both cases similar to a square wave, coherently with the displacement imposed on the drum.

The dynamic friction coefficient $\left(\mu_{\mathrm{d}}\right)$ is calculated as the average value of the friction coefficient curve, in the time interval where the velocity is certainly constant and the displacement of the drum is linear and continuous.

The static friction coefficient $\left(\mu_{\mathrm{s}}\right)$ is retrieved at the beginning of the sliding, corresponding to the peak in the friction coefficient curve, just before the sliding occurs. This peak represents the frictional resistance at first detachment (sliding) between the two surfaces in contact.

The static coefficient is in both cases (low and high temperature) greater than the dynamic friction coefficient. Nevertheless, comparing the two curves (Fig. 13), it is possible to highlight how the average value of the dynamic friction coefficient at ambient temperature is higher than the one calculated at higher temperature.

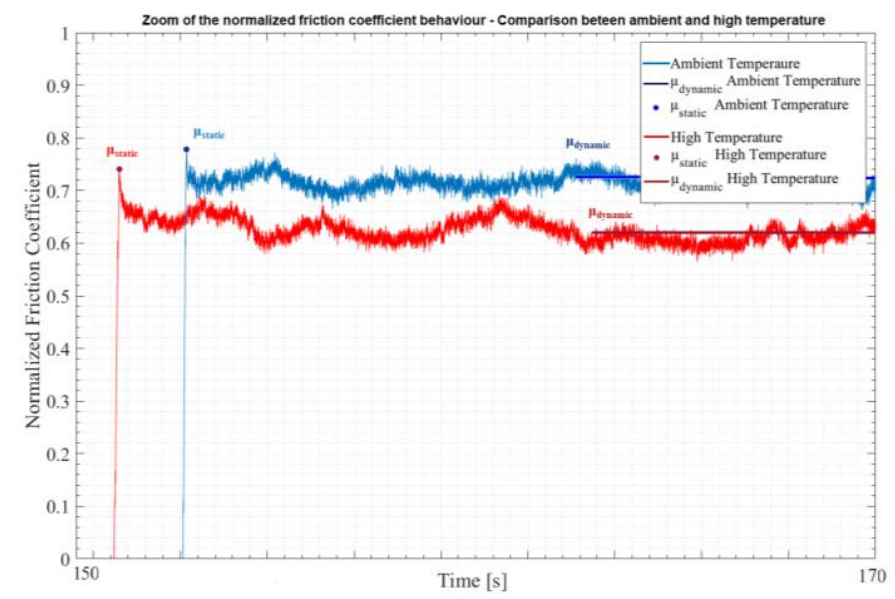

Fig. 13 Comparison between the normalized friction coefficient behaviour at ambient (blue curve) and higher temperature (red curve).

This difference is probably due to a change in the lubrication conditions, caused by the increase in temperature. On the contrary, the static friction coefficient stays approximately the same in the two tests. This means that, in the case of the high temperature, the transition from static to dynamic friction coefficient is sharper compared to the one at ambient temperature.

The difference between static and dynamic friction coefficient at higher temperature is twice larger than the one measured at lower temperature.

Higher difference between the static and the dynamic friction coefficients and, more specifically, the difference in the friction force during the sliding at higher temperature are sign of a different behaviour of the greased contact. An increase in temperature favourites the lubrication, decreasing the resistance force.
Accounting for the literature on stick-slip instabilities of dynamic systems, these results are in agreement with the occurrence of stick-slip in the braking phases at higher temperature, due to an increase of the gap between static and dynamic friction. In this case, the different response of the greased contact with the temperature is at the origin of the different vibrational response of the braking system.

\section{GENERAL CONCLUSIONS}

The occurring of vibrational instabilities is here consequence of an interaction between the system dynamics and the greased contact behaviour. The dynamic frictional system can thus become unstable, due to the local response of the contact, with respect to contact parameters such as sliding velocity. In the present work, the vibrational response and the contact surfaces have been analysed for a spring-brake system used in industrial applications to investigate stick-slip phenomena in greased contacts.

\section{A. Conclusions}

Thanks to the tests and the considerations made in the previous sections is therefore possible to conclude that:

I. The tests performed on the full brake system highlighted the vibrational (acceleration) response of the whole system in the two cases: absence and presence of stick-slip. In the case of presence of vibrational instability, the frequency spectrum shows how the system natural frequencies are excited by impulsive excitations, producing an increase in the vibration of the whole system. The analysis of the acceleration spectra allows for recognizing the appearance of the stick-slip phenomenon. Stick-slip occurs only after a certain number of cycles, when the internal brake temperature reaches about $70^{\circ} \mathrm{C}$.

II. Moreover, the brakes were analysed after being

disassembled, taking into account the two situations: a brake system how has performed two cycles and a brake system how have performed six cycles and how present vibrational instability. The observation of the greased contact surfaces shows a concentration of contact pressure in a limited area. On this area there are several marks due to the normal operating conditions of the system. These marks are the signs of the radial displacement of the spring, which widening and contracting its diameter to allow the braking or the sliding of the load, marks the surface in a radial direction with respect to the axis of the cylinder (i.e. the drum). particular traces of sticking and after sliding of the spring. However, in the case of temperature tests $\left(70^{\circ} \mathrm{C}\right)$ there are also traces different from the previous ones. The traces indicate an axial breath of the spring that moves in a direction parallel to the cylinder axis. Thought the surface analysis has been

$17^{\text {th }}$ LACCEI International Multi-Conference for Engineering, Education, and Technology: "Industry, Innovation, And Infrastructure for Sustainable Cities and Communities", 24-26 July 2019, Jamaica. 
possible to identify that, during the braking with stick-slip, the torsional spring does not remain in the original position during frictional stick-slip instabilities. The attempt of the spring to open axially can cause a misalignment of the components, a modification of the spring torsional stiffness, and a localization of the contact pressure. The presence of stick-slip, identified thanks to the acceleration signals and their spectrogram has been confirmed with the signs on the contact surface topographies.

III. The unstable dynamic response of the system is consequence of the frictional contact behaviour. For this reason, an investigation of the local frictional response of the greased contact has been performed.

Frictional tests have been then performed both at ambient and high temperature $\left(70^{\circ} \mathrm{C}\right)$, simulating contact conditions as close as possible to the ones on the real spring-brake system. Taking into account the lubricated contact, the static coefficient is in both cases greater than the dynamic friction coefficient. Comparing the two curves it was possible to highlight how the average value of the dynamic friction coefficient $\left(\mu_{\mathrm{d}}\right)$ at ambient temperature is higher than the one calculated at higher temperatures. Consequently, the difference between static and dynamic friction coefficient is higher at high temperature, in a non-negligible percentage.

All the reported results allow for identifying the presence of stick-slip system vibrations (periodic impulsive vibrations) in presence of a large difference between static and dynamic friction coefficient, due to the response of the greased contact to the boundary conditions imposed by the system.

\section{B. Future works and perspectives}

The performed dynamic and tribological analyses give a general overview of the stick-slip phenomena in greased contact for an industrial application mechanism. However, several contact parameters can affect the response of the vibrating system, such as contact normal load, sliding velocity, surface roughness, component geometries, material properties, types and conditions of lubrication.

The full understanding of the conditions for which the system is more predisposed to the stick-slip phenomenon may allow for preventing the appearance of such instabilities before its occurrence. This understanding is essential to establish the recommendations necessary for the development, industrialization and mass production of the brake systems.

In successive experimental tests, other contact and system parameters will be varied, in order to obtain a complete scheme of the involved parameters. The tests will be associated as well with numerical modelling, in order to have a complete and predictive view of the stick-slip in lubricated systems.

\section{REFERENCES}

[1] D. Tonazzi et al., 'Numerical analysis of contact stress and strain distributions for greased and ungreased high loaded oscillating bearings', Wear, vol. 376-377, pp. 1164-1175, 2017.

[2] I. Ghezzi et al., 'Damage evolution and contact surfaces analysis of highloaded oscillating hybrid bearings', Wear, vol. 406-407, pp. 1-12, Jul. 2018.

[3] R. A. Ibrahim, 'Friction-Induced Vibration, Chatter, Squeal, and Chaos-Part II: Dynamics and Modeling', Applied Mechanics Reviews, vol. 47, no. 7, p. 227, 1994.

[4] D. Tonazzi, F. Massi, A. Culla, A. Fregolent, and Y. Berthier, 'Role of damping on contact instability scenarios', in $5^{\circ}$ World Tribology Congress, Turin, Italy, 2013.

[5] J. Brunetti, F. Massi, W. D'Ambrogio, and L. Baillet, 'Steady state of modal coupling instabilities as a dynamic energy equilibrium', presented at the Proceedings of ISMA 2014 - International Conference on Noise and Vibration Engineering and USD 2014 - International Conference on Uncertainty in Structural Dynamics, 2014, pp. 1827-1842.

[6] S. M. Rubinstein, G. Cohen, and J. Fineberg, 'Visualizing stick-slip: experimental observations of processes governing the nucleation of frictional sliding', Journal of Physics D: Applied Physics, vol. 42, no. 21, p. 214016, 07-Nov-2009.

[7] A. Culla, D. Tonazzi, F. Massi, and A. Fregolent, 'Response surface model of a brake system to optimize structural modifications for squeal noise suppression', presented at the 41st International Congress and Exposition on Noise Control Engineering 2012, INTER-NOISE 2012, 2012, vol. 2, pp. 932-943.

[8] D. Tonazzi, F. Massi, L. Baillet, J. Brunetti, and Y. Berthier, 'Interaction between contact behaviour and vibrational response for dry contact system', Mechanical Systems and Signal Processing, vol. 110, pp. 110121, 2018.

[9] B. Feeny, A. Guran, N. Hinrichs, and K. Popp, 'A Historical Review on Dry Friction and Stick-Slip Phenomena', Appl. Mech. Rev, vol. 51, no. 5, pp. 321-341, May 1998

[10] R. I. Leine, D. H. V. Campen, and A. D. Kraker, 'Stick-Slip Vibrations Induced by Alternate Friction Models', p. 14.

[11] D. Tonazzi, F. Massi, L. Baillet, A. Culla, M. Di Bartolomeo, and Y. Berthier, 'Experimental and numerical analysis of frictional contact scenarios: from macro stick-slip to continuous sliding', Meccanica, vol. 50, no. 3, pp. 649-664, Mar. 2015.

[12] C. Gao, D. Kuhlmann-Wilsdorf, and D. D. Makel, 'The dynamic analysis of stick-slip motion', Wear, vol. 173, no. 1, pp. 1-12, Apr. 1994.

[13] M. D. Bartolomeo, F. Morelli, D. Tonazzi, F. Massi, and Y. Berthier, 'Investigation of the role of contact-induced vibrations in tactile discrimination of textures', Mechanics \& Industry, vol. 18, no. 4, p. 404, 2017.

[14] D. Tonazzi et al., 'Experimental and numerical characterization of system response under dry frictional contact', Proceedings of ISMA 2014 - International Conference on Noise and Vibration Engineering and USD 2014 - International Conference on Uncertainty in Structural Dynamics, 2014, pp. 1931-1946.

[15] J.-J. Sinou, J. Cayer-Barrioz, and H. Berro, 'Friction-induced vibration of a lubricated mechanical system', Tribology International, vol. 61, pp. 156-168, May 2013.

[16] G. Reiter, A. L. Demirel, J. Peanasky, L. L. Cai, and S. Granick, 'Stick to slip transition and adhesion of lubricated surfaces in moving contact', The Journal of Chemical Physics, vol. 101, no. 3, pp. 2606-2615, Aug. 1994.

[17] J. B. Sampson, F. Morgan, D. W. Reed, and M. Muskat, 'Studies in Lubrication: XII. Friction Behavior During the Slip Portion of the Stick-Slip Process', Journal of Applied Physics, vol. 14, no. 12, pp. 689700, Dec. 1943.

[18] P. A. Thompson and M. O. Robbins, 'Origin of stick-slip motion in boundary lubrication', Science, vol. 250 , no. 4982, pp. 792-794, Nov. 1990.

[19] R. Bruhn, ‘Tubutor motor', US6700246B1, 02-Mar-2004.

$17^{\text {th }}$ LACCEI International Multi-Conference for Engineering, Education, and Technology: "Industry, Innovation, And Infrastructure for Sustainable Cities and Communities”, 24-26 July 2019, Jamaica. 
[20] E. Lagarde and F. Negrello, 'Spring brake for the actuator of a screen for a building and actuator equipped with such brake', EP2230415A1, 22Sep-2010.

[21] E. Lagarde and D. Menetrier, 'Actionneur électrique d'entraînement d'un écran domotique', EP2267330A1, 29-Dec-2010.

[22] A. Tranchand, 'Actionneur électromécanique, installation de fermeture ou de protection solaire comprenant un tel actionneur et procédé de contrôle d'un tel actionneur', EP2746526A1, 25-Jun-2014.

[23] F. Schädlich, 'Actuator for driving an automatic sunscreen and facility including such an actuator', EP2821583B1, 23-Dec-2015.

[24] S. S. Antoniou, A. Cameron, and C. R. Gentle, 'The friction-speed relation from stick-slip data', Wear, vol. 36, no. 2, pp. 235-254, Feb. 1976.

[25] G. Lacerra, M. Di Bartolomeo, S. Milana, L. Baillet, E. Chatelet, and F. Massi, "Validation of a new frictional law for simulating friction-induced vibrations of rough surfaces', Tribology International, vol. 121, pp. 468480, May 2018.

[26] A. Lazzari, D. Tonazzi, G. Conidi, C. Malmassari, A. Cerutti, and F. Massi, 'Experimental Evaluation of Brake Pad Material Propensity to Stick-Slip and Groan Noise Emission', Lubricants, vol. 6, no. 4, p. 107, Dec. 2018.

$17^{\text {th }}$ LACCEI International Multi-Conference for Engineering, Education, and Technology: "Industry, Innovation, And Infrastructure for Sustainable Cities and Communities”, 24-26 July 2019, Jamaica. 